to keep the button driving, i. e., to keep the litharge molten and thus in a condition to run down the sides of the button and in most part to be absorbed by the cupel-even though the cupel and contents are drawn forward to a cooler position. With a gentle draught through the muffle the temperature one-quarter inch above and near the front of the cupel may be maintained as stated by one text, ${ }^{1}$ as low as $625-650^{\circ} \mathrm{C}$. and cupellation continued, although the danger of freezing is very much lessened if the temperature is kept between $650^{\circ}$ and $750^{\circ}$. So long as the heat of combustion of the driving button is able to maintain the temperature of the lead at that of melting litharge the cupellation proceeds. If the cupel is brought so near the mouth of the muffle that the transference of heat from the button is sufficiently rapid to overcome the heating effect of the combustion of the lead, the button cools; and when its temperature goes below the freezing point of molten litharge, it freezes, i. e., solid litharge covers the molten lead and cupellation ceases.

If the surrounding air is kept well below the temperature of nelting litharge, the surface of the cupel around the driving button becomes cooled below that temperature, and the molten lead oxide as it runs off the convex surface of the lead, solidifies, and crystals of litharge, or "feathers" form. These thin crystals volatilize slowly after forming, but do not disappear as a rule unless the temperature of the cupel surface is raised above $906^{\circ} \mathrm{C}$. when they melt and are partly absorbed by the bone ash of the cupel.

UNIVERSITY OF UTAF,

Salt lake City.

\section{A NICKEL CRUCIBLE FOR THE DETERMINA- TION OF CARBON IN STEEL.}

BY HENRY E. K. RUPPEL.

Received November 27, 1908.

The high price of platinum crucibles for carbon determinations led the writer to seek some substitute to supplement the work of the Shimer crucible in regular use in his laboratory. Nickel naturally suggested itself for this purpose on account of its inexpensiveness, its high melting point and its resistance to oxidation. Crucibles of this material have been used for the past year for the determination of carbon in steel and the results, obtained both by direct combustion of

I Richard W. Lodge: "Notes on Assaying" (1905), page 60. the steel and by solution in potassium copper chloride, have been so satisfactory that it seemed advisable to publish them together with a description of the apparatus.

At the beginning, a word should be said in regard to the conditions under which such crucibles can be used to advantage. A conservative estimate of the life of these crucibles is about thirty to fifty determinations when the solution method is used. On account of the low cost of these crucibles they can be used to advantage in those analytical laboratories where the number of carbon determinations performed is limited and the high initial cost of platinum precludes its use, especially in college laboratories where a single crucible may serve the needs of an entire class. They may also find a place as supplementary crucibles in steel laboratories where carbon determinations are a matter of daily routine. Since such crucibles are used up in time, it is necessary to make them as simple as possible and to provide for a separate water jacket not directly attached to the crucible.

The principle of a water-cooled stopper for platinum crucibles to be used in the determination of carbon in steel was first published by P. W. Shimer ${ }^{1}$ and several forms are at present on the market. Although the present paper is intended solely to show that satisfactory results can be obtained with a nickel crucible, nevertheless the writer feels justified in giving a somewhat detailed description of the cooling apparatus as the design is particularly adapted to the simple form of nickel crucible employed.

The apparatus is shown in Fig. I and 2 . Fig. I is a top view and Fig. 2 is a vertical section through the dotted line $x y$. It consists of three parts; the nickel crucible $A$, the cover $C$ and the water jacket $B$. The nickel crucible is $I 7 / 8$ inches deep, I 9/I 6 inches in diameter at the mouth and is provided with a flange about $9 / 16$ inch wide. These crucibles are now supplied to us in one piece, although we have used ordinary nickel crucibles to which a brass rim was soldered with silver solder. The area of the bottom was made comparatively large so that all the carbon might be in contact with the bottom of the crucible, even though the asbestos pad was made slightly large as sometimes happens. When this occurs with the platinum crucible, in which the

1 "Carbon Combustion in a Platinum Crucible," J. Am. Chem. Soc., 21, 7 (1899). 
area of the bottom is small, the asbestos pad as well as the asbestos used to wipe out the funnel, extends up the sides of the crucible. In such cases we have sometimes encountered unburnt carbon. This difficulty is further obviated by using a deep crucible which can be heated to a considerable distance from the bottom. It might be stated against this that an asbestos pad made in an ordinary funnel is not too large to fit comfortably in the bottom of the regular platinum crucible. On the other hand, the filtration becomes slower as the area of the pad decreases. We use a special funnel which will be described later and which offers a comparatively large area for filtration.
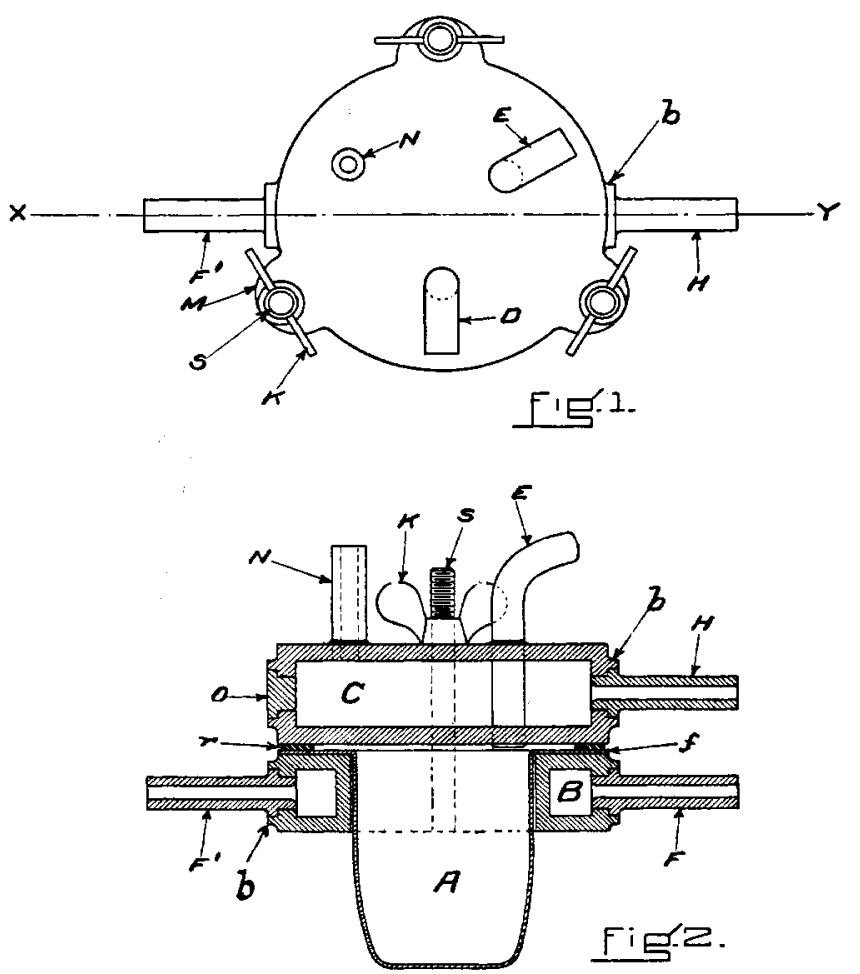

The crucible rests upon the water jacket $B$, which consists of an annular machined bronze casting $23 / 4$ inches outside diameter, I 9/I6 inches inside diameter and $5 / 8$ inch high with walls about $\mathrm{I} / 8$ inch thick. This jacket is provided with two $3 / 8$ inch holes, each of which is surrounded by a boss $b$. The holes are slightly counter-bored and the collars of the brass tubes $F$ and $F^{\prime}$ are inserted and fastened with ordinary solder. The brass tubes are all turned from solid stock and are $I / 4$ inch outside diameter with $I / 8$ inch holes. Three brass rods $S, 3 / 16$ inch in diameter and threaded at each end, are perma- nently soldered to the ears, corresponding to $M$ (Fig. I) with which the jacket is provided, and pass through holes in the corresponding parts of the cover which is keyed down by means of the winged nuts $K$.

The cover $C$ is also cast of bronze and machined. It is $23 / 4$ inches in diameter, $7 / 8$ inch high with walls about $I / 8$ inch thick. It is supplied with three semi-circular ears $\mathrm{M}, 3 / 4$ inch in diameter, through which holes are drilled to admit the rods $S$. In making these castings it was necessary to provide two $3 / 8$ inch holes through which the anchors of the core might be passed. One of these holes is closed by the brass plug $O$ (Fig. 2), the other is counter-bored and the collar of the brass tube $H$ inserted and soldered. The joint between the crucible and the cover is made tight by means of a rubber gasket $r$ such as is used for ordinary glass preserve jars. The air enters the crucible by tube $D$ (Fig. I), which extends I I/4 inches below the cover, and leaves by the tube $E$. The top ends of these tubes were bent in an ordinary blast lamp after filling them with sand. When in use tubes $F$ and $H$ are connected by means of a rubber tube. The water, supplied by an eighth-inch tap, enters the jacket at $F^{\prime}$ and leaves the cover through the tube $N$.

The cost of the nickel crucible is one dollar and ten cents. The cost of the completed jacket and cover, exclusive of patterns, is about seven dollars.

The determinations given in Table I were made by dissolving the steel in double potassium copper chloride solution, filtering on ignited asbestos, and burning in a current of air. The crucible was supported through a hole in a piece of asbestos board $\mathrm{r} / 4$ inch in thickness and was heated to bright redness for $3 / 8$ to $\mathrm{I} / 2$ inch from the bottom by mean of a small upright blast lamp. The time of heating was half an hour for steel and three-quarters of an hour for cast iron. Instead of using an ordinary funnel for filtering the carbon, we employed a modified form of the funnel generally used to support a Gooch crucible, in which the height of the funnel above the stem is about one inch. A copper wire is made into a close spiral at one end and passed through the stem of the funnel, loose asbestos is added, followed by a suspension of asbestos in water. After applying the suction, the asbestos is gently tamped down with the flattened end of a glass stirring 
rod. The finished pad is from $3 / 4$ to one inch in diameter and about $\mathrm{r} / 4$ inch thick. This pad is placed in the crucible with the carbon down and the crucible is filled loosely with ignited asbestos. The bottom is protected by means of sheet platinum shaped so as to fit snugly inside and to extend about $\mathrm{I} / 4$ inch up the sides.

The combustion train consists of a small preheating furnace containing a twelve-inch porcelain tube filled with copper oxide, followed by a Liebig bulb containing potassium hydroxide solution and a small guard tube. Next in order comes the crucible, a small furnace with a twelveinch porcelain tube containing copper oxide, a tube of beads moistened with water, a Marchand drying tube and the Geissler bulb and guard tube. The writer prefers the small porcelain tubes to the brass tubes frequently used and employs them with the platinum crucible. The above procedure is the one regularly used on carbon steels in his laboratory.

In Table I, column $I$, are given some of the results obtained with the nickel crucible, column 2 contains the corresponding results obtained with the platinum crucible, except in the case of cast iron, in which the results given in column 2 are the average of the results of various chemists on standard foundry iron. The results are representative and were not selected on account of their agreement. Blanks can be easily obtained showing an increase in weight of less than 0.5 milligram and the results agree closely with those

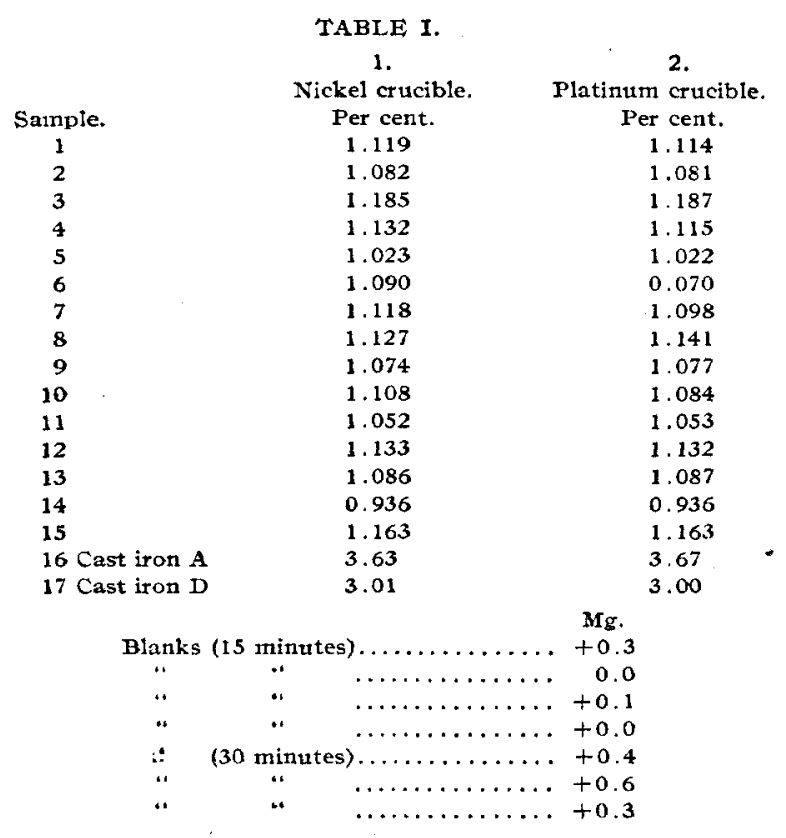

obtained by means of the platinum crucible. Many of the samples were mixtures from several rolls so that some of the variations may be due to imperfect mixing.

In Table II, column I, are given the results obtained by direct combustion of steel in a current of oxygen. In column 2 are given the corresponding results found by dissolving the steel in potassium copper chloride and burning the carbon in air.

To prevent the caked iron oxide from adhering to the platinum shell, which protects the bottom of the crucible, it is filled to a depth of about $1 / 16$ to $1 / 8$ inch with ignited aluminum oxide, which is tamped down in the middle with the flattened end of a glass rod. Three grams of steel are carefully placed on the aluminum oxide so as not to touch the sides of the platinum. After filling the crucible with loose asbestos the steel is burned for thirty minutes in a current of oxygen. Air is then passed through the apparatus for at least thirty minutes to remove the oxygen. The samples used for the direct combustion of steel consisted of pieces about $1 / 16$ inch square and about 0.006 inch thick. The iron oxide is readily removed at the end of the determination by withdrawing the platinum shell from the crucible. To prevent the platinum from adhering to the crucible it is advisable to remove it occasionally, especially while the crucible is new.

$\begin{array}{ccc} & \text { TABLE II. } & \\ \text { Sample. } & \mathbf{1 .} & \mathbf{2 .} \\ 1 & \text { Direct combustion. } & \text { Solution method. } \\ 2 & \text { Per cent. } & 1.137 \\ 3 & 1.123 & 1.144 \\ 4 & 1.151 & 1.133 \\ 5 & 1.144 & 1.163 \\ 6 & 1.176 & 1.163 \\ 7 & 1.153 & 1.114 \\ 8 & 1.109 & 0.834 \\ & 0.841 & 1.276\end{array}$

The following figures give some of the blanks obtained by passing oxygen through the apparatus for thirty minutes and expelling the oxygen by forcing air through for the same time:

+0.9 mg., +0.8 mg., + I. I mg., +0.7 mg., +0.4 mg., +0.3 mg.

When the direct combustions in oxygen were first tried, the air was allowed to pass through the combustion train for only fifteen minutes to expel the oxygen, but the results obtained in this way were always too high. That this was mainly due to the presence of oxygen in the Geissler bulb is shown by the following experiments. After 
attaching the weighed Geissler bulb to the train, oxygen was passed through at the rate of three bubbles per second for thirty minutes, followed by air at the same rate for fifteen minutes. The Geissler bulb was then detached and weighed, after standing in the balance case for fifteen minutes. The increase in weight was $7.4 \mathrm{mg}$. in one experiment and $5.2 \mathrm{mg}$. in another. While the bulb was in the balance case, air was passed through the rest of the train in order to remove any oxygen which might have been present. The Geissler bulb was again attached and air allowed to bubble through for fifteen minutes more. After allowing the bulb to remain in the balance case for the usual time, its weight was found to be practically the same as at the beginning of the experiment. This would seen to indicate clearly that the oxygen is not completely removed by passing air through the apparatus for fifteen minutes.

Many chemists do not expel the oxygen in this way but prefer to weigh the bulb containing oxygen instead of air; this would, of course, shorten the time considerably.

In conclusion, the writer desires to express his sincerest thanks to Professor Henry Fay for his interest and to his assistant, Miss Caroline E. Shute, by whom many of the determinations were made.

Boston, Mass.

\section{DETERMINATION OF IRON IN BRASSES AND BRONZES.}

By I. M. Bregowsky ANd L. W. Spring.

Received January 15, 1909.

At various times we have had occasion to compare our analyses of brasses and bronzes with those of other chemists, on the same samples. It has practically always been noticeable that while the other chemists check us within fairly close limits on tin, lead, copper and zinc-the main constituents of brass, they nearly always either fail to mention the iron content, or report it as "a trace" or give some such value as 0.06 per cent., or possibly 0.20 per cent.-seldom more. With samples on which our determinations of iron have shown the iron content to be far above "a trace" in any sense of the term, the chemist of a well-known railroad made no mention of iron in his report, and a prominent commercial chemist reported "a little iron present" on one of the two samples, and did not mention iron in the report on the other. With another sample on which we got 0.75 per cent. iron, a metal refiner offered to wager us a snug sum that there was not over 0.006 per cent. of iron present. His chernist had reported a content of 0.003 per cent.

Now iron in the amounts present in the commercial copper alloys may or may not be considered to be a factor of importance in the usefulness or working of the alloy, yet the chemist should know what the iron content is, or at least know how to determine it when he wants it. There is little that is new in the method and many will say that such accuracy is unnecessary. However, when occasion requires some may profit by a knowledge of it.

Fresenius' "Quantitative Analysis," Cohn edition, I904, p. 68I, says that the stannic oxide obtained upon the ignition of the metastannic acid precipitate is impure, containing part of the iron, besides other impurities, and gives directions for separation. We have found, as a rule, approximately half of the iron content of the brass in the ignited stannic oxide, unless the iron in the alloy is high. The remainder will be found by precipitation with ammonia either before or after the copper is separated, if sufficient time be allowed for it to come down. Our procedure is as follows:

A gram of the magnetted borings is dissolved and run down in nitric acid (I.42), the metastannic acid filtered out as usual and ignited to stannic oxide in a clean weighed porcelain crucible. After weighing the stannic oxide, one gram of c. p. sodium carbonate and 0.25 gram of sublimed flowers of sulphur are added, the crucible covered and the mixture fused at a very low heat until the excess of sulphur is burned off. Crucible and cover, when cold, are immersed in $50 \mathrm{cc}$. of distilled water in a No. I beaker and warmed to disintegration of the melt. They are then rinsed and removed. If the solution is blue or green, it indicates dissolved iron which can be thrown out by addition of a little ammonium chloride, leaving the solution a light yellow. The ferrous sulphide is filtered out, rinsed with hydrogen sulphide water, dissolved from the filter, and the iron determined by titration or gravimetrically. The iron figured to ferric oxide should, of course, be deducted from the weight of the stannic oxide.

The lead and copper are removed and determined by any of the usual methods. The filtrate is brought to a boil, the iron oxilized with 
a few drops of nitric acid and an excess of ammonia added. The solution is kept just at the boiling point for an hour or so. A bubble going up occasionally does no harm, but hard boiling does not allow the iron hydroxide to settle and undoubtedly has led many to believe that none was present. In an hour, the bottom of the beaker will show a considerable precipitate of iron hydroxide. It is filtered out, washed well with hot water, and determined volumetrically or gravimetrically. Blanks should be run on all chemicals used and their iron content allowed for.

We of en analyze magnetted drillings from brasses from many sources and seldom find one with an iron content of less than 0.40 per cent., and many run to 0.90 per cent. and above. Below are given some of our analyses showing the total iron found and the relative amounts found in the stannic oxide and the main solution. Many of these samples have been analyzed by other chemists who, in their original analyses, found little or no iron, but who now by this method check the results here given.

Brasses and Bronzes (Finished Goods) of Various Manufacturers.

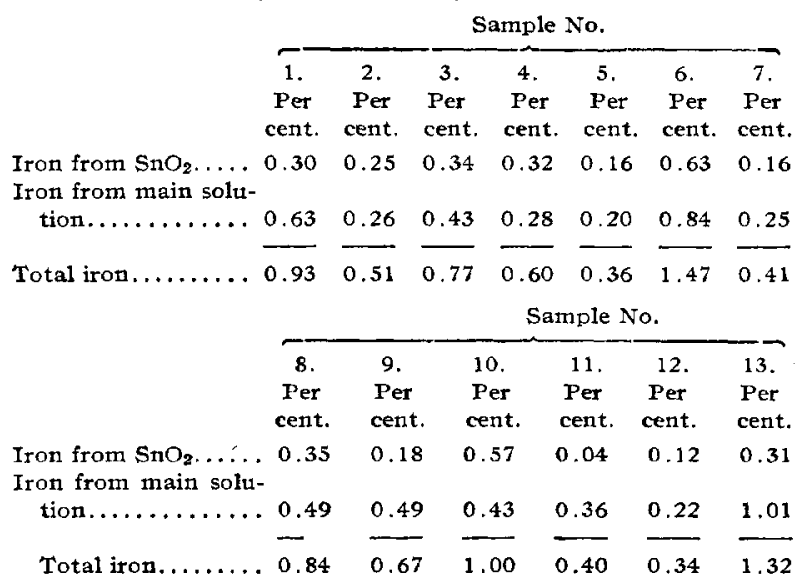

Nos. 6 and 13 were not manganese bronzes but ordinary brasses.

Brass ingots we have received from refiners gave:

\begin{tabular}{|c|c|c|c|c|c|c|}
\hline & \multicolumn{6}{|c|}{ Sample No. } \\
\hline & $\begin{array}{c}14 \\
\text { Per } \\
\text { cent. }\end{array}$ & $\begin{array}{l}15 . \\
\text { Per } \\
\text { cent. }\end{array}$ & $\begin{array}{l}16 . \\
\text { Per } \\
\text { cent. }\end{array}$ & $\begin{array}{c}17 \\
\text { Per } \\
\text { cent. }\end{array}$ & $\begin{array}{c}18 . \\
\text { Per } \\
\text { cent. }\end{array}$ & $\begin{array}{c}19 . \\
\text { Per } \\
\text { cent. }\end{array}$ \\
\hline $\begin{array}{l}\text { Iron from } \mathrm{SnO}_{2} \ldots \ldots \\
\text { Iron from main solu- }\end{array}$ & 0.39 & 0.37 & 0.24 & 0.24 & 0.22 & 0.33 \\
\hline $\operatorname{tion} \ldots \ldots \ldots \ldots \ldots$ & 0.34 & 0.33 & 0.28 & 0.98 & 0.49 & 0.32 \\
\hline Total iron. & 0.73 & 0.70 & 0.52 & 1.22 & 0.71 & 0.65 \\
\hline
\end{tabular}

Samples of brass borings received from metal dealers, after removal of the free iron by magnet, gave:

\begin{tabular}{|c|c|c|c|c|c|}
\hline & \multicolumn{5}{|c|}{ Sample No. } \\
\hline & $\begin{array}{c}20 . \\
\text { Per } \\
\text { cent. }\end{array}$ & $\begin{array}{c}21 . \\
\text { Per } \\
\text { cent. }\end{array}$ & $\begin{array}{c}22 . \\
\text { Per } \\
\text { cent. }\end{array}$ & $\begin{array}{l}23 . \\
\text { Per } \\
\text { cent. }\end{array}$ & $\begin{array}{l}24 . \\
\text { Per } \\
\text { cent }\end{array}$ \\
\hline $\mathrm{SnO}_{2}$ & 0.20 & 0.28 & 0.21 & 0.28 & 0.29 \\
\hline on $f$ & 0.35 & 0.35 & 0.63 & 0.43 & 0.32 \\
\hline & 0.55 & 0.63 & 0.84 & 0.71 & .61 \\
\hline
\end{tabular}

These results are sufficient to show that the ordinary copper alloy contains considerably more than "a trace" of iron. How necessary it is in a technical analysis to determine this iron is, of course, for the individual chemist or metallurgist to say. They also show that the quantity of iron carried down by the tin is, in the main, proportional to the amount of tin in the alloy.

Sample above No.

Per cent. of tin in the

11. $12 . \quad$ 13. 8.4 2. 10.6 .

$\begin{array}{lllllllll}\text { alloy.............. } & 1.13 & 2.28 & 3.34 & 8.20 & 6.04 & 5.97 & 5.67\end{array}$

$\begin{array}{llllllll}\text { Per cent. of iron in } \mathrm{SnO}_{2} & 0.04 & 0.12 & 0.31 & 0.35 & 0.25 & 0.57 & 0.63\end{array}$

Undoubtedly the varying gelatinous condition of metastannic acid also influences the quantity of iron which is carried down.

Crane Co. laboratory,

Chicago, January, 1909.

(CONTRibution from the Chemical laboratory of the North Carolina Agricultural EXPERIMENT Station.)

\section{THE COLORIMETRIC DETERMINATION OF NITRATES IN SOIL SOLUTIONS CONTAINING ORGANIC MATTER.}

\author{
By W. A. SYME. \\ Received December 9, 1908.
}

The accurate determination of nitrates in soil solutions by the colorimetric method with phenoldisulphonic acid and ammonia is a matter of some difficulty on account of the large number of interfering substances which may be present in the solution. Chlorides may cause a loss of nitric acid when the phenoldisulphonic acid is added to the residue left on evaporation. Iron salts affect the color. Nitrites interfere by producing a yellow color with the reagents like that caused by nitrates. These disturbing factors can be removed to a considerable extent-the chlorides by adding silver sulphate, the iron salts with sodium carbonate, and the nitrites may be determined separately by the Griess method.

The presence of organic matter in the soil extract causes trouble in several ways. In the first place, the solution may be so intensely colored that it cannot readily be decolorized with carbon black; secondly, the organic matter may reduce 